\title{
O HORROR AO FRANQUISMO REPRESENTADO NO FILME, "O LABIRINTO DO FAUNO”, RETRATADO NO INCONSCIENTE DA CRIANÇA À LUZ DA HISTÓRIA E DA PSICANÁLISE
}

\begin{abstract}
Liliane Cirino Vieira ${ }^{1}$
RESUMO: Os horrores da Guerra Civil Espanhola e do período da ditadura fascista do general Francisco Franco foram abordados em diversas obras da historiografia, da literatura e da arte espanhola. Entre elas, encontramos a obra cinematográfica O Labirinto do Fauno (2006), em que assinala, o entrecruzamento e o diálogo paralelo entre realidade e ficção, ao retratar a vida de uma menina, Ofélia, no regime autoritário e opressor franquista. Neste artigo, temos por objetivo, o estudo e desenvolvimento de algumas narrativas, que possibilitam examinar como se constrói, por meio da fiç̧ão, uma memória da resistência antifranquista, a partir de memórias inconscientes dos conflitos de classe e da crueldade deste regime caudilhista, analisando pelo viés da psicologia analítica.
\end{abstract}

Palavras-chave: Guerra Civil Espanhola. Fascista. Caudilho. Historiografia. Cinematográfica. Realidade. Ficção. Psicologia Analítica.

ABSTRACT: The horrors of the Spanish Civil War and the period of the fascist dictatorship of General Francisco Franco were addressed in several works of historiography, literature and Spanish art. Between them, we find the cinematographic work The Labyrinth of the Fauno (2006), in which it marks, the intercrossing and the parallel dialogue between reality and fiction, when portraying the life of a girl, Ophelia, in the authoritarian and oppressive regime Franco. In this article, we aim to study and develop some narratives that allow us to examine how fiction builds a memory of anti - Franco resistance, from unconscious memories of the class conflicts and cruelty of this caudillo regime, analyzing by the bias of analytical psychology.

Keywords: Spanish Civil War. Fascist. Caudillo. Historiography. Cinematographic. Reality. Fiction. Analytical Psychology.

\section{INTRODUÇÃO}

Este trabalho tem a finalidade de investigar a possibilidade de um exercício de construção da história a partir da ficção, analisando o que representou a política franquista.

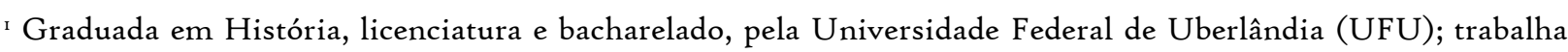
como professora na empresa Secretaria de Educação do Estado de Minas Gerais. Possui também especialização em psicopedagogia clínica e institucional pelo Instituto Passo i e é mestranda no curso de pós-graduação em História na UFU. Email: psiqquezor8@gmail.com
} 
E ele se desenvolve num contexto em que alguns ideais "neofascistas" estão colocados novamente com o advento do governo Bolsonaro, ${ }^{2}$ no Brasil. Em virtude disso, o filme " $O$ Labirinto do Fauno" foi selecionado por ser caracterizado, por alguns, como cinema fantástico. Esse exercício corrobora exatamente com a intenção de tentar extrair, ao máximo, as possibilidades de se construir a história a partir do que é considerado fantasioso ou ficcional.

O filme se mostra muito intrigante e, em decorrência disto, assisti uma dezena de vezes e, desde já, devo avisar que, porventura, ele contém spoiler. Existem já alguns trabalhos, descritos nas referências, que caminham por um viés semelhante, entretanto, não com o mesmo objetivo específico.

O enredo, que "mistura realidade e imaginação em um mesmo plano3", se passa no contexto do governo do general Francisco Franco na Espanha, que ficou conhecido como franquismo, e conta a história do inconsciente da personagem menina, Ofélia, traduzido no medo de algo que o filme sugere que ela não conhecia, o fascismo, mas que existiu, mesmo sem o seu conhecimento.

A película foi escrita e dirigida por Guillermo Del Toro, ${ }^{4} e$, mesmo não obtendo o prêmio do festival de Cannes, constitui uma bela forma de penetrar o imaginário de quem quer entender um pouco do que representa o terror para os excluídos e explorados que viveram sob o domínio despótico do regime fascista/franquista. "A escolha pela linguagem simbólica dos contos de fadas para retratar tal período impressiona e nos envolve. E, apesar de parecer um filme infantil, não se trata apenas disso5." 4

Obviamente, é necessário um recorte do que podemos representar como a realidade ou fantasia/ficção, sendo que, a análise deve ser precedida por outras fontes e métodos que nos trazem vestígios dos fatos provenientes do acontecimento histórico a ser investigado. Isto não significa que a fiç̧ão não tenha relevância, já que, ela mesma também faz parte da história e do pensamento, além de acrescentar riqueza poética inenarrável ao texto historiográfico.

\footnotetext{
${ }^{2}$ ARIAS, Juan. Como Bolsonaro, Mussolini iniciou a instauração do fascismo com ameaças ao Parlamento e à liberdade de expressão. El País, o5 de Maio de 2020.

${ }^{3}$ BUTCHER, Pedro. Del Toro cria bela narrativa fantástica sobre o medo. In: Jornal Folha de São Paulo, Ilustrada. I de dezembro de 2006.

${ }_{4}^{4}$ Guillermo Del Toro é um cineasta, roteirista e produtor mexicano. Criado pela sua avó, Del Toro desenvolveu interesse por cinema quando adolescente. Diretor de "Cronos", filme que o projetou internacionalmente em I993; 5 “Mutação", 1997; "Hellboy”, 2004; e “A Espinha do Diabo", 200ı. (BUTCHER, Pedro. 2006). Idem.
} 
Em determinado período histórico, os signos e léxicos podem ter muita relevância para determinado lugar e cultura, todavia em outros, podem não traduzir nenhum significado simbólico. Ou seja, é preciso reconhecer a necessidade de explicar os fatos políticos, e, ao mesmo tempo, o enredo que envolve os personagens mitológicos, como o fauno, ${ }^{6}$ por exemplo. Vários escritores, poetas e pintores já retrataram fatos que representam a história da Espanha, tais como por exemplo, os pintores Francisco José de Goya y Lucientes 7(1746-1828) e Pablo Picasso (1881-1973) que, em Guernica, a famosa pintura cuja inspiração obteve do caos e sofrimento gerado pelo bombardeamento da cidade que leva o mesmo nome do quadro, ${ }^{8}$ em 26 de abril de 1937 pelos alemães durante a Guerra Civil Espanhola, expressa, em imagem, as sensações e o horror da guerra. Tida como arte cubista, ela não deixa de ser um importante registo histórico. Também o poeta e dramaturgo espanhol, Federico Garcia Lorca ( ${ }^{9}$ I898-1936), uma das primeiras vítimas da Guerra Civil, dentre outros autores.

Não obstante, a escolha do trabalho com esse filme, enquanto um documento e fonte histórica, ou, por exemplo, em uma sala de aula, representa um enorme desafio, já que, precisamos lapidar as arestas, mostrando profundo conhecimento teórico/metodológico acerca do tema em questão. Levando em conta que, o que representa a "fantasia" em meio à "realidade" é permeado de mitos ${ }^{\text {Io } e ~ l e n d a s, ~ q u e ~ t a m b e ́ m ~ f a z e m ~ p a r t e ~ d a ~ h i s t o ́ r i a ~ e ~ d o ~}$ imaginário coletivo em determinado período e lugar histórico. Sendo que esta ficção tem significados diferentes em momentos e lugares históricos diferentes.

\section{CONFLITOS E CONVERGÊNCIAS ENTRE A REALIDADE E A FICÇÃO NO FILME "O LABIRINTO DO FAUNO"}

Em consonância com a historiografia sobre história e fiç̧ão, este artigo traz a intenção de dialogar historicamente com o filme $O$ Labirinto do Fauno e sua relação com a história do franquismo, após a guerra Civil Espanhola (1936-1939) dialogando também com a

\footnotetext{
${ }^{6}$ A mitologia do fauno será explicada logo abaixo.

7 Fase do romantismo, Goya retratava paisagens, cenas mitológicas, religião, deuses, demônios, feiticeiros e a realeza. Em I82ı foi processado pela inquisição.

${ }^{8}$ Localizada no País Basco.

${ }_{9}$ Nascido em Andaluzia, autor de Poemas do Canto Fundo (1921-1922), Romancero Gitano (1928), do poema A las cinco de la tarde, dentre outros.

1o $\mathrm{O}$ novo minidicionário escolar da língua portuguesa de Dermival Ribeiro Rios traz um significado interessante do mito, que seria um "fato histórico ou personagem real exageradamente representados pela imaginação popular".
} 
psicanálise. Dessa forma, "há um cruzamento entre história e literatura, mediatizado pela narrativa cinematográfica, configurando-se em dois planos que interseccionam". "Nesta película, Guillermo Del Toro rompe as barreiras entre o real e o ficcional trazendo-os em dois planos que dialogam paralelamente.

O monstro ${ }^{12}$ de Ofélia tem a função de expressar o imaginário coletivo do que representou o horror inconsciente, expresso na violência do regime fascista traduzindo os conflitos antagônicos de classe e dos ideais republicanos e nacionalistas, para uma criança que viveu naquele período. Sabemos, obviamente, que, nem todas as crianças vivenciaram as mesmas experiências na Espanha naquele período. Todavia, ele nos apresenta uma história singular de uma menina órfã, amante de contos de fada, que viveu ${ }^{13}$ sob o domínio do regime brutal e opressor.

Assim, o personagem do Homem Pálido nos remete, simbolicamente, a imagem de um "monstro", devorador de crianças, que vive escondido detrás das paredes, traduzindo o imaginário do horror, permeado de narrativas fantasiosas, fábulas, lendas, mitos e contos de fadas lidos nos livros infantis. E também o Fauno, ser mitológico considerado como paganismo pela cultura cristã ocidental, que é representado em algumas culturas latinas, representa essas agruras.

Neto de Saturno, o fauno era cultuado como divindade romana dos campos e pastores, profética e brincalhona, semelhantes aos Sátiros gregos e a Pã, "deus dos bosques, das florestas e dos rebanhos, que morava em grutas, vagava pelas montanhas e pelos vales e divertia-se caçando ou dirigindo as danças das ninfas", seria a personificação da natureza. Era temido por aqueles que atravessavam as matas durante a noite, "pois as trevas e a solidão que reinavam em tais lugares predispunham os espíritos aos temores supersticiosos” causando-lhes terror e pânico. ${ }^{14}$

A fabulação é a válvula de escape de um mundo violento, mas não há uma separação clara entre aquilo que é concreto e o que é fantasia. O fauno que aparece

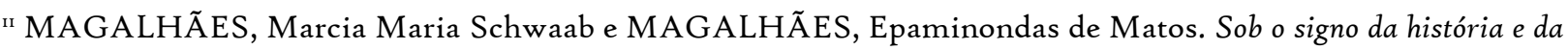
fiç̧ão: O Labirinto do Fauno. In: Revista ON-LINE. Barra do Garças (MT), vol. o2, n. or, p. ro6-I13, julho/dezembro de 2013.

${ }^{12}$ O Homem Pálido, devorador de crianças, possui os olhos nas mãos, é um personagem intrigante e, portanto, será abordado ao longo do trabalho.

13 A história da menina é ficcional, mas contém metáforas que representam poeticamente, para Del Toro, o inconsciente da criança sob o regime franquista.

${ }^{14}$ BULFINCH, Thomas. O livro de ouro da mitologia. Rio de Janeiro: Ediouro, 2006, p. 20 e i67.
} 
para a jovem Ofélia (a menina Ivana Baquero, ótima) é tão real quanto seu padrasto, o tirano capitão Vidal (vivido por Sergi López, de "Pintar ou Fazer Amor"). Ora bolas: as criaturas imaginárias, se são imaginadas, passam a existir. Elas fazem parte do real e, ainda que não possam ser tocadas, têm igual importância na vida daqueles que as imaginam. ${ }^{\text {I5 }}$

As crianças, assim como os homens, as mulheres, os velhos, os "loucos", os excluídos, e toda gama de sujeitos, também fazem parte da história. Claro que, as crianças possuem uma forma peculiar e fantasiosa de enxergar o breve percurso em que vivem como tal, já que, ao crescer, muitas não se recordam da sua infância. O que não significa que isto não tenha relevância para a história propriamente dita.

A história é ambientada nas montanhas de Navarra, Espanha, em 1944, quando a Guerra Civil já havia acabado, deixando como saldo o triunfo e dominação do general Francisco Franco. ${ }^{16} \mathrm{~A}$ trama da película se divide em dois mundos ou planos aparentemente opostos, que convivem paralelamente, sendo que, um deles é o plano da magia, onde Ofélia é uma princesa que fugiu para o submundo, e precisa cumprir uma missão expressada rigorosamente em três tarefas, que deveriam ser realizadas em total sigilo. Essas tarefas foram impostas pelo fauno, para que ela possa sair da opressão em que vive, e encontrar-se no seu verdadeiro lar, o reino encantado, representando supostamente a libertação do mundo físico.

Já no plano da realidade, ${ }^{17}$ a história engendrada mostra o cenário de um sítio aonde o temido e severo capitão Vidal gere uma espécie de quartel militar, em que manifesta uma política violenta e autoritária aos moldes do franquismo, impondo aos camponeses e agregados pobres uma vida de racionamento, fome e austeridade, enquanto, contraditoriamente, os militares vivem com fartura. Ele tranca a comida em um galpão e institui uma cota mínima de alimentos, impossível de sobreviver.

Durante o regime franquista, a miséria se fez presente através de sua política

\footnotetext{
is BUTCHER, Pedro. Del Toro cria bela narrativa fantástica sobre o medo. In: Jornal Folha de São Paulo, Ilustrada. I de dezembro de 2006.

${ }^{16}$ Francisco Franco nasceu em 1892 na cidade de Ferrol, na Espanha. Entre 1912 e 1926 se destacou nas campanhas bélicas no Marrocos Espanhol, com breves interrupções. Em 1923 recebeu a patente de tenente-coronel e assumiu o comando da Legião Espanhola. Em 1926, Francisco Franco chegou a general. Em 1928 passou a dirigir a Academia Militar de Saragoça. De 1931 a 1936 foi instalada uma Segunda República. Em 1934 participou da Revolução de Astúrias. Em 1935 foi o comandante chefe do Exército Espanhol no Marrocos e em 1936 converteuse a Chefe do Estado Maior. Governou a Espanha de 1939 até 1975 copiando os modelos nazifascistas do italiano Mussolini e alemão, Adolf Hitler. Faleceu em Madri, Espanha, no dia 20 de novembro de 1975. (FRAZÃO, Diva) Disponível em: https://www.ebiografia.com/francisco_franco/ acesso em: 17/o6/2018.

${ }^{17}$ Utilizo entre aspas porque essa mesma realidade também pode ser considerada uma ficção.
} 
econômica. O salário médio de um operário em 1936 girava em torno de io pesetas, e já em I95I, em torno de II a I8 pesetas. Sendo que, foi lançada uma proclamação sobre o pão, base da alimentação familiar, que encarecia tremendamente a alimentação ${ }^{18}$

Poucos dias após as declarações de Franco e do ministro da Indústria e do Comércio sobre o início de uma nova era de prosperidade e abundância, os preços dos produtos essenciais para a população se elevaram em proporções escandalosas. $\mathrm{O}$ arroz, de Io pesetas o quilo, passou a I3 e I4; em 1936, o quilo do arroz custava 8 o cêntimos; o grão de bico e o feijão se elevaram na mesma proporção, o azeite de oliva desapareceu do mercado e o que estava à venda só podia ser comprado por milionários; o azeite em 1936, custava I,80 o litro, agora é vendido a 35 e 40 pesetas o litro; o toucinho que em 1936 era vendido a 2,50 o quilo, hoje custa de 5o a 60 pesetas; a carne que em 1936 custava 4 pesetas, hoje custa 70; o metro de tecido de algodão, que em 1936 custava o,8o ou I,20, no mês de julho do ano passado custava, na Espanha, I4 pesetas; após o levantamento das sanções contra o regime franquista elevou- se a 30 pesetas o preço do metro. Os tecidos de lã subiram nesse mesmo período de 130 para 300 pesetas. $\mathrm{O}$ calçado aumentou em 50\%. Mas com o pão foi mais escandaloso. O pão é, desde que existe o regime franquista, $\mathrm{um}$ artigo de luxo para os trabalhadores. $\mathrm{O}$ racionamento do pão é hoje na Espanha, de Ioo a I5o gramas para os trabalhadores, mas não de pão branco e sim de uma mescla intragável de farinhas que nunca foram utilizadas na Espanha no fabrico de pão.

O objetivo do quartel também consistia em eliminar os guerrilheiros, derradeiros rebeldes da Guerra Civil, que resistiam bravamente nas montanhas, utilizando-se de táticas de guerrilha contra o regime opressor. E, mesmo não sabendo de nada disso, Ofélia percebia e expressava sua angústia através da imaginação, confundindo a realidade com as fábulas que lia nos livros de contos de fadas.

Ofélia é uma menina de dez a onze anos, órfã de pai, quando é levada para o casarão de Navarra pela sua mãe, Carmen, ${ }^{19}$ que, grávida do capitão Vidal, objetivava casar-se com ele, sendo que, Ofélia se tornaria sua enteada. Contudo, o capitão se mostra um homem meticuloso, soberbo e frio. Sua disciplina militar é expressa no relógio, herdado do pai, que ele observa e sempre carrega consigo, além da farda militar, que ele sempre usa. $O$ seu interesse imediato em Carmen consistia no herdeiro que ela carrega em seu ventre.

Até a Guerra Civil, a Espanha era um país agrícola e ainda permanecia sob a égide do absolutismo que girava em torno da figura do Rei Alfonso XIII. Os latifundiários representavam uma pequena parcela da elite agrária, e se beneficiavam de imenso poder, juntamente com a Igreja Católica, enquanto a maior parte que compunha o restante da população, era composta pelos braceros ${ }^{20}$. Há séculos:

${ }^{18}$ IBARRURI, Dolores, I95I.

19 Representada pela atriz Ariadna Gil.

${ }^{20}$ Camponeses sem terra que vendiam sua força de trabalho por valores ínfimos, mas só conseguiam trabalho 
O regime de propriedade da terra na Espanha era baseado fundamentalmente em um sistema de transmissão hereditária, denominado mayorazgo. Nesse sistema, a posse da terra era transmitida sempre ao primogênito da família. As terras herdadas, porém, não podiam ser divididas nem vendidas, só ampliadas. ${ }^{21}$

Não obstante, a realidade e a fantasia para algumas crianças podem ser confundidas, sendo que, podemos refletir sobre o que isso representa elas. A fantasia de Ofélia pode ser interpretada como um misto de escape e intuição inconsciente, levada a cabo pela necessidade de sobrevivência em meio a um ambiente hostil.

O capitão, desde o início, demonstra falta de apreço pela literatura que ela carrega, contrapondo-se a ela, uma suposta racionalidade científica, mostrando profundo desprezo e preconceito. Enquanto a realidade, traduz com metáforas, toda a áurea carregada de ódio, discriminação, violência e autoritarismo que representou o caudilhismo dos franquistas.

O filme apresenta aproximação com alguns dos arquétipos do psicanalista Carl Gustav Jung. ${ }^{22 "}$ "Os mitos e os contos, sob a luz da psicologia analítica, são a expressão e representação de acontecimentos psíquicos, assim como os sonhos. Utilizam-se de uma linguagem simbólica e dizem respeito às verdades mais profundas do ser humano". ${ }^{23}$

Segundo Jung, temos como atributos positivos do arquétipo materno "o que cuida, o que sustenta, o que proporciona condições de crescimento, fertilidade e alimento" e no seu aspecto negativo "o abissal, o mundo dos mortos, o devorador".

A obra também é repleta de símbolos do feminino refletindo a visão de mundo de Ofélia interagindo com fortes personagens, como Mercedez e Carmen. A primeira tarefa dada pelo Fauno à Ofélia é recuperar uma chave do estômago de um sapo gigante, que sugava a vida de uma antiga figueira na floresta. A cena é um misto de "Alice no País das Maravilhas"e ${ }^{24} \mathrm{da}$ busca do "retorno ao útero", convergindo na alusão ao mundo feminino, em que podemos observar, por fora, que a árvore é muito semelhante a um útero. O que nos remete a gravidez de Carmen ao apresentar as duas cenas paralelamente. No útero de Carmen existe uma criança real que está para nascer e cabe à Ofélia disputar sua consciência,

durante a colheita e o restante do ano não restava outra alternativa a não ser o banditismo e a guerrilha para sobreviver.

${ }^{21}$ MESSINA, Giselle Beiguelman. A Guerra Civil Espanhola. São Paulo: Scipione, 1994, p. 13.

${ }^{22}$ Psiquiatra e psicoterapeuta suíço, responsável por fundar a Psicologia Analítica. Nasceu no dia 26 de julho de 1875, na cidade de Kresswil, na Basiléia. Jung propôs e desenvolveu os conceitos da personalidade extrovertida e introvertida, arquétipos, e o inconsciente coletivo.

${ }^{23}$ GRAUPEN, Andrea e CAMPELLO, Lívia.

${ }^{24}$ Carroll, Lewis. Alice no País das Maravilhas, Lisboa: Publicações Dom Quixote, 2000. 
mesmo antes do nascimento. O Homem Pálido é uma criatura grande e flácida, sentado em frente a um grande banquete. Durante a sua segunda tarefa, Ofélia adentra através da parede em um mundo paralelo, e, olhando ao redor, ela vê pilhas de sapatos e retratos do monstro na parede, comendo crianças, que nos remete à descrição de Cronos de Goya. Claramente, o Homem Pálido é uma representação do inconsciente do poder opressivo do fascismo introduzido brutalmente no mundo de Ofélia, e nos evoca o Capitão Vidal, representante mor do franquismo na obra.

Paralelamente, ${ }^{25}$ para promover essa comparação, numa cena em que Vidal janta com seus convidados, incluindo um sacerdote católico, em que uma mesa farta é mostrada, o capitão Vidal demonstra seu autoritarismo patriarcal, onde não há espaço para questionar as vontades dele. Há, nessas duas cenas paralelas, uma nítida comparação entre o capitão e Homem Pálido.

Ofélia consegue recuperar o punhal, mas na sua saída, não pode resistir à tentação de comer uma suculenta uva, simbolizando a riqueza acumulada pelos números Cronos. Isso desperta o Homem Pálido, que imediatamente coloca seus globos oculares em suas mãos e começa a perseguir Ofélia, que quase não consegue escapar viva. Essa atitude de fugir das regras impostas pelo fauno, custou a vida de uma das fadas, o que despertou a fúria dele.

Em I844, os latifundiários espanhóis criaram a Guardia Civil, com a finalidade de reprimir a autodefesa dos camponeses. O resultado disso foi a institucionalização da violência e a transformação da Andaluzia em um palco de guerrilhas até a década de 30. A opressão do regime franquista também é expressada através da tortura no galpão do casarão de Navarra pelo capitão Vidal contra os rebeldes capturados.

O regime político franquista se inicia por volta de 1939 à 1975 na Espanha, e utiliza um discurso dos valores conservadores, reacionários, tradicionais, segregacionistas, autoritários, militaristas, religiosos, patrióticos, rurais, dentre outros valores retrógrados que evocam as desigualdades sociais, exclusão, barbárie. O objetivo principal era garantir o poder à elite agrária em contraponto ao imobilismo social imposto ao restante da população. E, mesmo a burguesia, que em outros países como na França, por exemplo, promoveram a queda da monarquia, na Espanha se aliou bem cedo às classes mais conservadoras. ${ }^{26}$

${ }^{25}$ Essa palavra é usada muitas vezes, pois é a que mais se adapta à narrativa em questão.

${ }^{26}$ MESSINA, Giselle Beiguelman, 1994. 
A política educacional ${ }^{27}$ do regime franquista centrava-se em modelos de escolas rurais $^{28}$ e na perseguição aos ideais republicanos, socialistas, comunistas e anarquistas nas escolas. Tratavam desses ideais como uma "contaminação das almas infantis". Bem antes disso, em 1926, os universitários já não encontravam representatividade, sendo que, eles haviam começado a se reunir em torno de agremiações políticas, como a Alianza Republicana e os ligados à esquerda Acción Republicana. Em decorrência disso:

Os primeiros anos do regime franquista foram especialmente rigorosos, sangrentos
e propícios à perseguição, quer no que diz respeito a livros nas bibliotecas e a
modelos e práticas pedagógicas inovadoras, quer, e em especial, na procura e
captura de professores que tivessem tido qualquer contacto com sindicatos de
esquerda, ou com correntes pedagógicas inovadoras como as de Celestin Freinet. ${ }^{29}$

Estas práticas repressivas e discriminatórias foram levadas às escolas primárias, secundárias e universidades. As consequências dessa política eram a prisão, erradicação, julgamentos político-ideológicos sumários, eliminação de livros com esses conteúdos nas bibliotecas, inibição do laicismo e o desmantelamento do projeto pedagógico republicano em geral, em que os ideais republicanos, já em 1938 perdiam mais terreno para os nacionalistas, se consolidando ao final da guerra em 1939.

Estima-se que, após a guerra, segundo dados militares, tenham sido executados entre 28 a 30 mil pessoas que lutaram contra o nacionalismo, 300 mil exilados e 8 mil entregues aos nazistas. Não obstante, apesar do nacionalismo ter saído vitorioso no regime franquista, não podemos nos esquecer da importância da resistência republicana. ${ }^{30}$

No filme, ao mesmo tempo que Ofélia cumpre as tarefas, os habitantes da casa, como a empregada Mercedes, cujo irmão é guerrilheiro, e o médico Dr. Ferreiro, simpatizantes dos republicanos, também saem clandestinamente da casa para completar missões de auxílio à resistência anti-franquista, como levar cartas, chaves, alimentos e medicamentos à milícia escondida nas montanhas.

Quando o general percebe que o médico ajuda o torturado que implora para morrer,

${ }_{27} \mathrm{O}$ artigo $43^{\circ}$ da Lei de Educação Primária de 1945 é muito explícito quando refere aos ideais da educação franquista (DIAZ, p. 73).

${ }_{28}^{28}$ DIAZ, José Maria Hernández. A escola rural em Espanha na primeira fase do franquismo (1939-I95I). In: Revista Lusófona de Educação, p. 66, 12, 2008.

29 Idem, p. 68.

3o IBARRURI, Dolores. A luta do povo espanhol contra o franquismo. In: Problemas - Revista Mensal de Cultura Política no 37 , Nov-Dez de 195 I. 
ele interpreta como uma traição, e, ao questionar sobre sua desobediência, o médico lhe responde:

'Es que, obedecer por obedecer, así, sin pensarlo, eso solo lo hacen gentes como usted, Capitán” ${ }^{31}$ (fala do personagem Doutor Ferreiro no filme).

Podemos observar que a história nos mostra a tortura como um dos métodos realmente utilizados na ditadura franquista:

Como prisioneira das forças do general Francisco Franco, depois da Guerra Civil Espanhola, Carmen Arrojo ${ }^{32}$ foi alimentada com lentilhas cozidas misturadas a cacos de vidro. No dia em que se rendeu, em 1939, viu um soldado republicano que preferiu cortar a garganta a se entregar. As experiências por que passou a atormentaram por décadas..$^{33}$

Um outro exemplo é de José María Galante, que, “quando universitário esquerdista foi algemado ao teto de uma câmara de torturas em um subsolo, ficando suspenso no ar". Seu torturador era Antonio González Pacheco. Entretanto, após a morte de Franco em 1975, a anistia "incentivou uma espécie de esquecimento coletivo, em nome da reconciliação". ${ }^{34}$

Assim, a simbologia do labirinto ${ }^{35}$ nos aponta o percurso de Ofélia, ao longo do filme, e nos revela as complicações e perturbações psíquicas causadas pelo regime político fascista às suas vítimas. Um percurso incerto e difícil afetado pela ruptura trágica da infância da menina, podendo ser interpretado como um dos fatores objetivos do inconsciente do horror de Ofélia e da fuga da realidade através da fantasia.

\section{CONSIDERAÇÕES FINAIS}

Neste trabalho, percebemos que a ficção também é um ótimo meio para analisarmos um determinado período histórico, em consonância com o uso de outras fontes, referenciais bibliográficos e uma metodologia diferenciada daquela que propõe a história enquanto ciência objetiva. Reconhecendo a história enquanto uma construção narrativa e de representação do/a historiador/a.

Avaliamos, portanto, a possibilidade de construção a partir dessa ficção, que pode

\footnotetext{
${ }^{31}$ Tradução: "É que, obedecer por obedecer, assim sem questionar, só o fazem gente como você, capitão".

${ }^{32} \mathrm{O}$ texto se refere a uma mulher que viveu na Espanha franquista e não à personagem Carmen do filme.

33 ROMAN, Mar. Espanha não esquece vítimas do franquismo. In: Jornal Folha de São Paulo, I3 de dezembro de 2004.

34 YARDLEY, Jim. Torturados pela ditadura de Franco buscam justiça na Espanha. Folha de São Paulo, 22/o4/2014.

${ }_{35} \mathrm{Na}$ mitologia grega, o labirinto de Creta teria sido construído por Dédalo para alojar o Minotauro, monstro metade homem, metade touro, a quem eram oferecidos regularmente jovens que devorava. Segundo a lenda, Teseu conseguiu derrotá-lo e encontrar o caminho de volta do labirinto graças ao fio de um novelo, dado por Ariadne, que foi desenrolando ao longo do percurso.
} 
ser considerada fonte histórica, já que faz parte da história e do pensamento, proporcionando também riqueza poética ao texto. A análise do filme dialoga com a psicanálise de Jung observadas através de mitos, lendas e contos de fada, dentre outras referências sobre a temática. Assim, o franquismo foi estudado em consonância com a obra de ficção cinematográfica

O Labirinto do Fauno, analisando o poder de figuras caudilhistas, nacionalistas e reacionárias, que emergem após a Guerra Civil Espanhola. Em que, o filme consegue obter, ao mesmo tempo, os componentes do real e do fantástico, dialogando paralelamente em dois planos aparentemente diferentes, mas, que se complementam, enquanto realidade/ficção no inconsciente coletivo expressado no conflito e no horror de Ofélia aos monstros.

A partir dessa análise, vimos, portanto, como o franquismo alimentava os conflitos de classe, já que, enquanto mantinha a miséria e a opressão dos camponeses de um lado, também obtinha a ostentação de poder e riqueza caudilhista do outro.

$\mathrm{Na}$ retrospectiva podemos perceber como a política educacional franquista foi fundamental para envolver a mentalidade das crianças no regime. Sendo que, ela centravase em modelos de escolas rurais, conservadores, anticomunistas e antirrepublicanos. Culminando na tortura contra os sujeitos que expressavam ideais opostos ao regime, em que interpretamos como uma forma de fuga da realidade através da fantasia.

\section{REFERÊNCIAS BIBLIOGRÁFICAS}

ALVES, Syntia Pereira e RIBEIRO, Joana Marques. Memória e mito entrelaçados em o Labirinto do Fauno. In: Revista Aurora. PUC- SP, 201 .

ANKERSMIT, F. R. Representação e Referência”. In: A escrita da História: a natureza da representação histórica. Londrina: Eduel, 2012.

BARRADAS, Adriana. Cinema Como Fonte Histórica: Possibilidades de Uma Nova História. In: Revista Livre de Cinema p. 20-33 v.I, n. 3, set/dez, 2014.

BOSCOV, Isabela. O labirinto do fauno. Revista Veja. Abril Comunicações S. A. o6/12/2006. BULFINCH, Thomas. O livro de ouro da mitologia. Rio de Janeiro: Ediouro, 2006. 
BUTCHER, Pedro. Del Toro cria bela narrativa fantástica sobre o medo. In: Jornal Folha de São Paulo, Ilustrada. I de dezembro de 2006.

CAMPELLO, Livia e GRAUPEN, Andrea. O labirinto do fauno: o percurso mítico de Ofélia. Psicólogas e Arteterapeutas, Pós-graduadas em Teoria e Prática Junguiana pela Universidade Veiga de Almeida (RJ). Disponível em: $\langle$ http://www.saindodamatrix.com.br/archives/2008/II/o_labirinto_do_fauno.html.〉. Acesso em: 17/o6/2018.

CERTEAU, Michel de. A história, ciência e ficção. In: História e psicanálise: entre ciência e ficção. 2 ed. BH: Autêntica, 2012, p. 45-70.

DIAZ, José Maria Hernández. A escola rural em Espanha na primeira fase do franquismo (1939195I). In: Revista Lusófona de Educação, I2, 2008.

FERREIRA, Letícia Schneider. O cinema como fonte da história: elementos para discussão. In: MÉTIS: história \& cultura, v. 8, n. I5, jan./jun. 2009.

GEORGE, Orwell. Lutando na Espanha: Homenagem à Catalunha, Recordando a guerra civil espanhola e outros escritos. São Paulo: Editora Globo, 2006.

HARO, Fernando Ampudia de. Gerir a dissidência: vencedores e vencidos na Espanha franquista. In: Análise Social, no 194. Lisboa, 2010.

IBARRURI, Dolores. A luta do povo espanhol contra o franquismo. In: Problemas - Revista Mensal de Cultura Política no 37, Nov-Dez de 1951. Disponível em: $\langle$ https://www.marxists.org/portugues/ibarruri/ano/mes/luta.htm\#topp〉. Acesso em: $17 / 06 / 2018$. 
JUNG, Carl Gustav. Os arquétipos e o inconsciente coletivo. São Paulo: Vozes, 2000.

JÚNIOR, Francisco das Chagas Fernandes Santiago. Cinema e historiografia: trajetória de um objeto historiográfico (I971-2010). In: História da historiografia. Ouro preto. Número 8, abril de 2012, p. 151-173. Disponível em: http://conexoesclinicas.com.br/wpcontent/uploads/2015/o5/jung-c-os- arquetipos-e-o-inconsciente-coletivo.pdf $>$. Acesso em: $17 / 06 / 2018$.

KOSELECK, Reinhart. Representação, evento e estrutura. In: Futuro Passado. Rio de Janeiro: PUC-Rio/Contraponto, 2006, p. 133-I47.

MAGALHÃES, Marcia Maria Schwaab e MAGALHÃES, Epaminondas de Matos. Sob o signo da história e da ficção: O Labirinto do Fauno. In: Revista ON-LINE. Barra do Garças (MT), vol. o2, n. oI, p. Io6-II3, julho/dezembro de 2013.

MESSINA, Giselle Beiguelman. A Guerra Civil Espanhola. São Paulo: Scipione, 1994.

MORAIS, Julierme. A historiografia do cinema brasileiro: perspectivas para uma abordagem teórico-metodológia. In: Revista Fênix. Vol. I3. Ano XIII, № I. Junho de 2016.

MORETTIN, Eduardo Victorio. O cinema como fonte histórica na obra de Marc Ferro. In: História: Questões \& Debates. Ed. UFPR. Curitiba, n. 38, p. II-42, 2003.

NAVARRETE, Eduardo. O cinema como fonte histórica: diferentes perspectivas teóricometodológicas. In: Revista Urutágua - revista acadêmica multidisciplinar - Quadrimestral, Maringá (PR). DCS/UEM - ISSN 1519-6178 № I6 - ago./set./out./nov., 2008.

O LABIRINTO do fauno. Direção: Guillermo Del Toro, Produção: Alfonso Cuarón e Alvaro Augustin, Produtora: Frida Torresblanco, México e Espanha, 2006. II9 minutos.

ROMAN, Mar. Espanha não esquece vítimas do franquismo. In: Jornal Folha de São Paulo. I3 de 
dezembro

de

2004

Disponível

em:

〈https://wwwi.folha.uol.com.br/fsp/mundo/ft13122004I5.htm>. Acesso em: 18/o6/2018.

RANCIÈRE, Jacques. As imagens querem realmente viver? In: ALLOA, Emmanuel (org.)

Pensar a Imagem. Belo Horizonte: Autêntica, 2015, p. 19i-204.

A política das imagens. RJ: Contraponto, 2012, p. 9-42.

SCHVARZMAN, Sheila. Marc Ferro, cinema, história e cinejornais: Histoire parallèle e a emergência do discurso do outro. In: ArtCultura, Uberlândia, v. 15, n. 26, p. 187-203, jan.-jun. 2013.

SOUSA, César Henrique Guazzelli. A história como montagem: contribuições do cinema para a crítica da historiografia. In: Domínios da Imagem, Londrina, ano VI, n. II, p. 25-38, novembro 2012.

ARIAS, Juan. Como Bolsonaro, Mussolini iniciou a instauração do fascismo com ameaças ao Parlamento e à liberdade de expressão. E1 País, o5 de Maio de 2020.

VAX, Louis. A arte e a literatura fantásticas. Lisboa: Arcádia, I974.

YARDLEY, Jim. Torturados pela ditadura de Franco buscam justiça na Espanha. Folha de São Paulo, 22/04/2014. 